\title{
PERFIL ACADÊMICO E PRODUTIVIDADE CIENTÍFICA DOS DOCENTES DE BIO(ÉTICA) NO ENSINO DA FONOAUDIOLOGIA DO RIO GRANDE DO SUL
}

\section{Academic Profile and Scientific Productivity of Teachers' Bio(ethics) in the Teaching of Speech Therapy of Rio Grande do Sul}

Tiago Pereira de Souza ${ }^{1}$

Erissandra Gomes ${ }^{2}$

\begin{abstract}
Resumo: A necessidade da aplicação dos conhecimentos em ética e bioética, na prática em saúde é cada vez mais emergente, dadas às transformações socioculturais que expõem o trabalhador a problemas éticos de complexidades imensuráveis. Na contramão desta demanda, as formações em saúde precarizam na quantidade e na qualidade do ensino destas temáticas. No sentido de contribuir com a problematização do ensino, esta pesquisa propôs estabelecer o perfil acadêmico e a produtividade científica dos docentes que ministram disciplinas de Ética e Bioética nas graduações de Fonoaudiologia no Rio Grande do Sul (RS), discutindo a inserção desses profissionais nas áreas ministradas. Para isso, se configurou em uma análise documental, descritiva exploratória e de caráter quali-quantitativo, usando como base de dados o conjunto de currículos disponíveis na Plataforma Lattes do Conselho Nacional de Desenvolvimento Científico e Tecnológico (CNPq). O estudo aponta, entre outros achados, que apenas quatro docentes são Fonoaudiólogos, demonstrou um importante distanciamento entre a atuação dos docentes e suas produções acadêmicas e científicas, com as áreas que ministram, além de evidenciar que a maioria dos docentes não possui em seus currículos nenhum indicador relacionado a ética e bioética. Propõe uma discussão a partir dos temas publicados nos artigos científicos: formação em Medicina; comunicação entre Médico e paciente; ensino da ética para a Medicina; confiança, autonomia e bioética. Percebe-se a urgência do debate sobre a formação, visando ampliar essa discussão, visto que, fica mais do que claro, que o ensino da ética e da bioética na Fonoaudiologia carece de atenção.
\end{abstract}

Palavras-chave: Ensino. Ética. Bioética. Fonoaudiologia.

\begin{abstract}
The need to apply knowledge in ethics and bioethics in health practice is increasingly emerging, given the socio-cultural transformations that expose workers to dilemmas. In view of this demand, health education is precarious in the quantity and quality of teaching on these topics. To contribute to teaching, this research aimed to establish the academic profile and scientific productivity of teachers in the disciplines of Ethics and Bioethics of undergraduate courses in Speech Therapy in Rio Grande do Sul (RS), discussing the insertion in these areas. It is configured in a documentary, exploratory, descriptive, qualitative and quantitative analysis,

\footnotetext{
${ }^{1}$ Mestre em Saúde Coletiva e Doutorando do Programa de Pós-Graduação em Educação em Ciências da Universidade Federal do Rio Grande do Sul (UFRGS). Orcid: https://orcid.org/0000-0001-6614-0047.

2 Doutora em Ciências Médicas e Docente do Programa de Pós-Graduação em Educação em Ciências da Universidade Federal do Rio Grande do Sul (UFRGS). Orcid: https://orcid.org/0000-0002-2379-7345.
} 
based on the curriculum of Lattes Platform of the National Council for Scientific and Technological Development $(\mathrm{CNPq})$. The study points out, among other findings, that only four teachers are speech therapists. It shows a gap between the performance and its academic and scientific productions, with the areas in which they teach. This shows that most teachers do not have any indicators related to ethics and bioethics. It proposes the discussion of themes published in scientific articles: training in Medicine; communication between doctor and patient; teaching ethics for medicine; trust, autonomy and bioethics. It is possible to perceive the urgency of the debate on training to expand this discussion, as it is evident that the teaching of ethics and bioethics in Speech Therapy needs attention.

Keywords: Teaching. Ethics. Bioethics. Speech, Language and Hearing Sciences.

\section{Introdução}

As Diretrizes Curriculares Nacionais em saúde (DCN) orientam a organização de Projetos Políticos-Pedagógicos e as Matrizes Curriculares dos cursos de graduação (BRASIL, 2001a). Desse modo, as DCN da formação do Fonoaudiólogo abordam a necessidade da existência e a relevância das dimensões éticas e humanísticas na formação. Espera-se formar profissionais embasados, capazes de agir frente a concepção sociocultural e econômica apresentada na sua prática, possibilitando por sua ação, transformações em benefício da sociedade (BRASIL, 2001a). Por outro lado, para isso acontecer, faz-se importante a existência da transversalidade fazendo com que essas perspectivas sejam conteúdo da matriz curricular em sua totalidade (MOTA; VÉRAS, 2020; SANTOS et al., 2020; WERNECK, 2020) e de disciplinas que proponham reflexões críticas sobre comportamento, na prática profissional (FINKLER; CAETANO; RAMOS, 2013).

É importante destacar, que nem todas as formações na área da saúde possuem a observância dos dispostos das DCN (COSTA et al., 2018). Cabe salientar, que a existência de disciplinas específicas não é um pressuposto de cumprimento das $\mathrm{DCN}$, visto que, se relacionam em alguns casos com a limitação do estudo da ética para, unicamente, a apresentação aos códigos que determinam condutas das profissões, nas quais as infrações são atribuídas ao cumprimento ou não dessas normativas, descrito por códigos de "ética" que, na verdade, dizem respeito a parâmetros legais que estabelecem o que se deve ou não fazer, bem como suas sanções (deontologia) (ANDRADE; GIVIGI; ABRAHÃO, 2017).

O que muitas vezes é esquecido, tanto no ensino quanto na prática, é que os códigos são escritos pelos próprios profissionais, humanos, limitados e suscetíveis a erros. Nesse aparato deontológico existe uma "suposição de verdades", de modo que, quando são constatadas suas fragilidades ao dar conta das tensões e complexidades do cotidiano, culpa-se a falta de fiscalização ou busca-se a produção de mais códigos, portarias, legislações, resoluções e regulamentos (ANDRADE; GIVIGI; ABRAHÃO, 2017). Na verdade, a formação necessita da concepção de que a ética está relacionada a uma atitude de crítica e crise, em que pensamos a ética singularmente, questionando a homogeneização das relações propostas nos códigos (FOUCAULT; MOTTA, 2008). A formação deve preparar o egresso para lidar com as situações em que o código fracassa, fazendo com que ele se confronte consigo mesmo, com a relação com os outros e com as verdades previamente estabelecidas (ANDRADE; GIVIGI; ABRAHÃO, 2017).

Os conhecimentos éticos e bioéticos adquiridos na graduação, devem ser aplicados no cotidiano do cuidado em saúde. A ação irá se estabelecer quando o egresso estiver frente a um problema ético, ou seja, quando deverá escolher um, entre diferentes caminhos que podem ser 
seguidos do ponto de vista da indagação terapêutica, ética, moral ou social (ALCÂNTARA, 2020). O docente é um dos principais atores na construção da cena de formação do egresso em Fonoaudiologia, cabendo-lhe o importante papel para além do ensino de conteúdos estabelecidos de pesquisa e ética profissional, de ser também uma referência para a concepção do estudante, por sua postura e prática humanizada (FERREIRA; MOUR ÃO; ALMEIDA, 2016; FINKLER; CAETANO; RAMOS, 2013; NÓBREGA et al., 2015; WERNECK, 2020). A aproximação com as temáticas e a educação permanente se efetua importante neste processo, já que possibilita a ressignificação de saberes e elaboração de novos conhecimentos (ARANTES et al., 2017). Além disso, a construção de saberes através de pesquisas, no sentido de busca contínua e indagações sobre a temática (FREIRE, 1997) e, por consequência publicações na área, também viabiliza uma maior imersão no que tange a prática docente (FERREIRA; MOURÃO; ALMEIDA, 2016).

A tríade ensino-pesquisa-extensão é indissociável, por isso a produção acadêmica dos docentes é um dado a ser considerado quando um estudo se propõe a avaliar a imersão dos mesmos em temáticas específicas, dado que, é público que tais sujeitos devam não somente conseguirem transmitir, mas também produzir conhecimento (PIROLA et al., 2020; YAMAMOTO et al., 2012). Importante destacar que os projetos de pesquisas, podem contemplar a participação dos discentes, fato que também contribui para a comunidade científica, forma recursos humanos qualificados para a sociedade e colabora para a formação intelectual, moral, crítica e criativa do acadêmico (PINHO, 2017; PIROLA et al., 2020).

Sendo assim, este estudo objetiva analisar o perfil acadêmico e a produtividade científica dos docentes que ministram disciplinas de Ética e Bioética nas graduações de Fonoaudiologia no Rio Grande do Sul, discutindo a inserção desses profissionais nas áreas abordadas.

\section{Metodologia}

Trata-se de uma análise documental, descritiva exploratória e de caráter qualiquantitativo, realizada no período de fevereiro a março de 2021, que utilizou como técnica a documentação indireta, visando fazer um levantamento sobre informações existentes sobre a temática de interesse (SOUZA et al., 2021). Esta pesquisa teve como base de dados o conjunto de currículos disponíveis na Plataforma Lattes do Conselho Nacional de Desenvolvimento Científico e Tecnológico (CNPq), de preenchimento compulsório desde 2002 para todos os pesquisadores. Reconhece-se aqui as fragilidades de tal plataforma no que tange seu sistema, atualização e capacidade culminando, por exemplo, em indisponibilidade de acesso neste ano.

Foram utilizados para buscar as informações nos currículos os Descritores em Ciências da Saúde (DeCS): ética, bioética e suas traduções em espanhol (ética y bioética) e inglês (ethics and bioethics). Os dados foram coletados manualmente em uma planilha "on-line" no mês de março de 2021. O objetivo desta sistemática foi organizar as informações e facilitar a análise da pesquisa, com vistas a tabulação dos seguintes dados: IES; tempo de atuação na IES; vínculo institucional; última atualização do currículo; biografia informada pelos docentes; titulação; disciplinas ministradas na graduação de Fonoaudiologia; projetos de pesquisa; projetos de extensão; artigos completos publicados em periódicos; livros publicados/organizados ou edições e capítulos de livros publicados.

A partir da análise das Matrizes Curriculares, dispostas no site das sete IES que formam Fonoaudiólogos no RS, foi possível selecionar como critério de inclusão apenas os cursos que possuem disciplinas de Ética e Bioética em sua formação. De modo que, uma IES não foi 
incluída no estudo, pois não possui disciplinas em sua grade relacionadas às temáticas. A partir da seleção das seis IES (três públicas e três privadas), foi possível buscar a lista de docentes dos cursos em seu site institucional. As graduações que não possuíam a lista de docentes disponíveis em seu site, foram contatadas por endereço eletrônico, formalizando a disponibilização dos nomes dos docentes para a realização da pesquisa, sendo possível coletar as informações das seis instituições incluídas, encontrando treze docentes das disciplinas estudadas.

Os indicadores derivados das publicações de artigos científicos se dividem em três principais categorias: indicadores de publicação; indicadores de citação; indicadores de ligação (DAVYT; VELHO, 2000). Nesse trabalho optamos por estudar os indicadores de publicação, que medem o número de documentos (artigos completos publicados em periódicos; livros publicados/organizados ou edições e capítulos de livros publicados), devido às limitações no acesso aos dados de citações e de coautoria na plataforma, não garantindo a confiabilidade necessária. Os dados quantitativos de produção já mencionados, foram apresentados a partir de estatística descritiva. Para avaliar o perfil dos docentes, foram analisados o texto base, indicado na biografia do Currículo Lattes. Para avaliar o conteúdo das produções (artigos) foram analisados os resumos e as conclusões.

O pressuposto teórico escolhido para a análise das publicações foi a Lei de Zipf, que se refere a frequência em que as palavras ocorrem num dado texto, gerando uma lista ordenada de termos de uma determinada disciplina ou assunto (CARRAPATO; CORREIA; GARCIA, 2017; CASSETTARI et al., 2015). Tal pressuposto, estabelece as ocorrências em comparação às palavras-chave. Esta aplicação é utilizada para qualificar todas as palavras presentes no corpus textual e, assim, entender o assunto ou até comparar se as palavras-chave selecionadas pelo autor tem realmente alguma ligação com o conteúdo geral (CASSETTARI et al., 2015). Os dados qualitativos retirados das biografias informadas pelos docentes e dos resumos e conclusões dos artigos, foram transformados em textos únicos e salvos em extensão ".txt", por ser o formato padrão exigido pelo programa IRAMUTEQ (Interface de $R$ pour les Analyses Multidimensionnelles de Textes et de Questionnaires), software utilizado para processamento dos dados (CAMARGO; JUSTO, 2013). Após, passaram por uma rígida revisão para verificar a existência de assimetrias textuais, palavras que o dicionário do programa não decodificaria, bem como a adequação de sinônimos, flexões de verbos, pronomes e caracteres desconhecidos, para a padronização do corpus textual (CAMARGO; JUSTO, 2013).

Para a avaliação dos dados retirados das biografias e artigos, utilizaram-se as ferramentas para aplicação do cálculo de frequência de palavras (Lei Hipergeométrica) e análise de similitude apresentada pelo escore de coocorrência (CAMARGO; JUSTO, 2013; MARCHAND; RATINAUD, 2011). A escolha de tais processos foi estabelecida pela compatibilidade dos dados apresentados ao programa e, por demonstrarem eficiência e eficácia no processamento dos mesmos, para posterior inferência de significados aos gráficos e grafos gerados.

\section{Resultados}

Foram analisados 13 currículos de docentes de ética e bioética (três homens e dez mulheres) de seis IES. Os currículos analisados foram identificados como letras, aleatoriamente, conforme Quadro 1. 
Revista de Educação, Ciência e Tecnologia

Quadro 1 - Caracterização do perfil acadêmico dos docentes de ética e bioética dos cursos de graduação de Fonoaudiologia do RS.

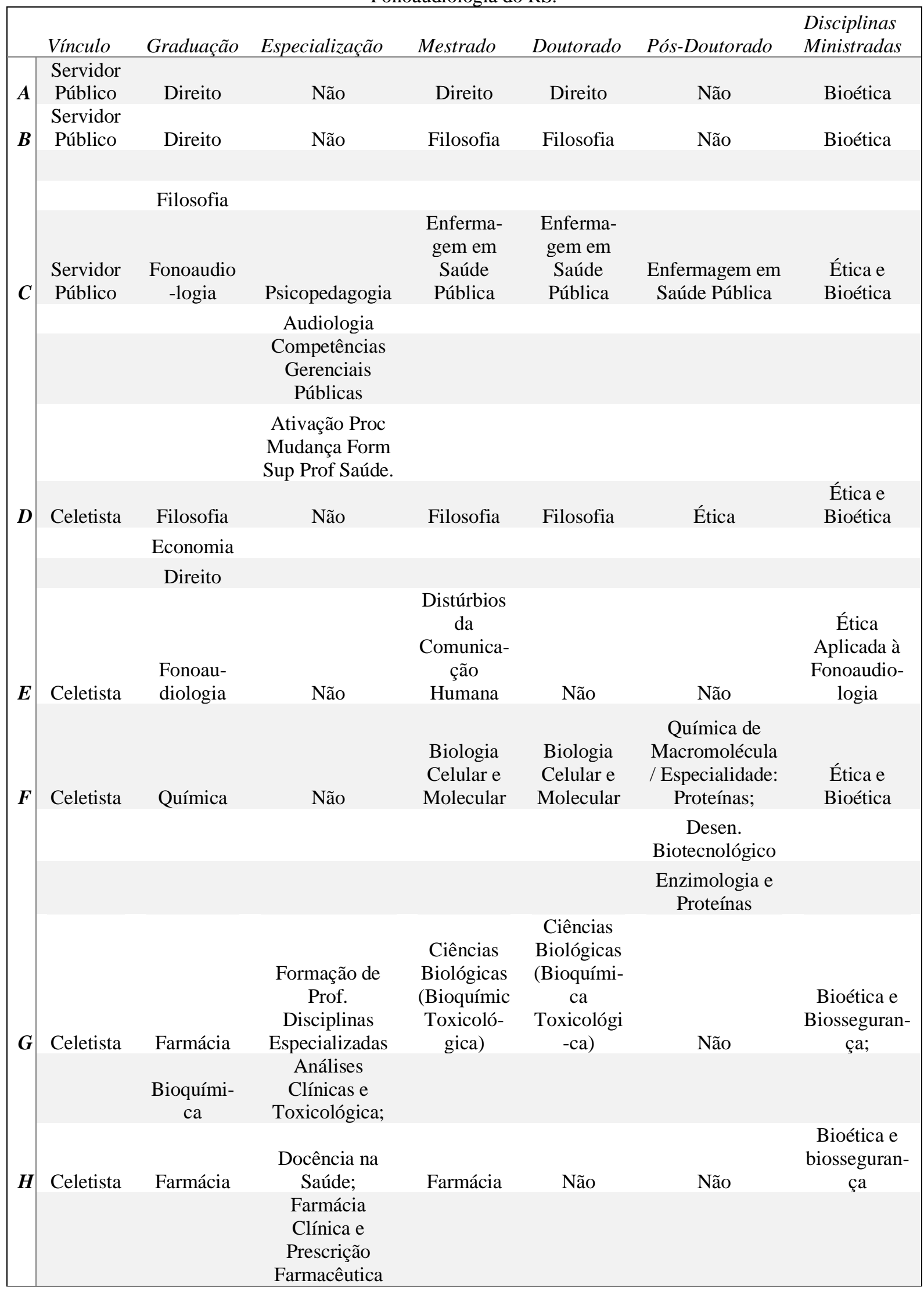




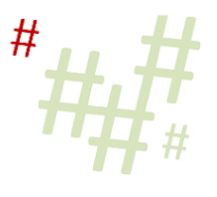

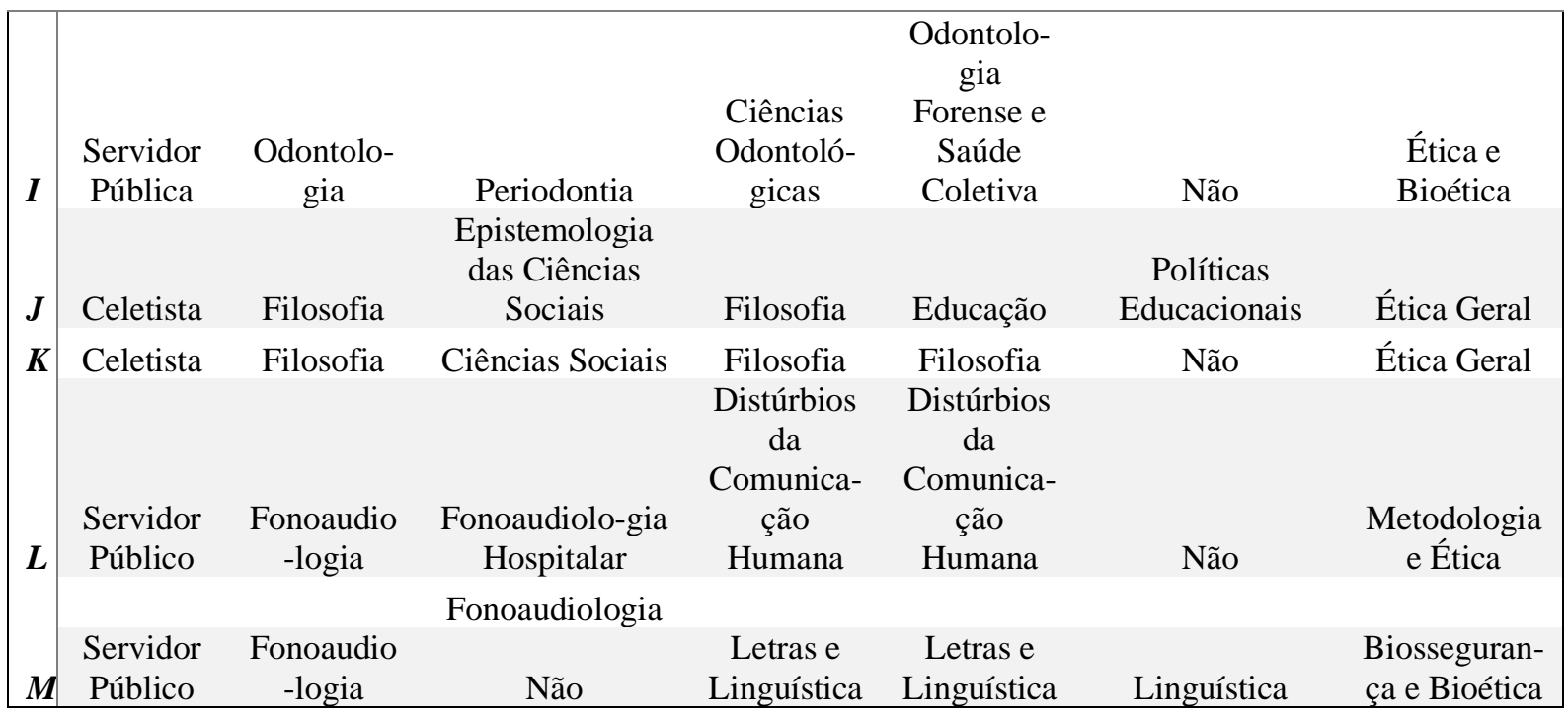

Fonte: Autores (2021).

Quanto à vinculação profissional, a maioria dos docentes é celetista com uma média de tempo de atuação na IES de 12 anos, enquanto servidores públicos possuem uma parcela menor, com média de atuação de aproximadamente sete anos nas instituições. As áreas de graduação predominantes são a Filosofia e a Fonoaudiologia, seguidas do Direito, e Farmácia com dois docentes cada, e com um docente por profissão, temos: Economia; Química; Bioquímica e Odontologia. O número total de graduações é superior à quantidade de currículos avaliados, pois um mesmo docente apresentou mais de uma formação de nível superior. As disciplinas ministradas pelos docentes podem ser classificadas em: bioética, ética e, por último, ética aplicada à Fonoaudiologia.

As especializações estão presentes em sete currículos. A formação docente, ciências farmacêuticas e as ciências sociais são mencionadas como pós-graduações concluídas por quatro docentes, além de psicopedagogia, audiologia, competências gerenciais públicas e ativação: processos de mudança na formação superior de profissionais da saúde, todas realizadas pelo docente " $\mathrm{C}$ ", fonoaudiologia hospitalar e fonoaudiologia pelo docente " $\mathrm{L}$ " $\mathrm{e}$ periodontia concluída pelo docente "I". Os docentes A, B, D, E, F e M não possuem o nível de especialização.

Esta situação difere quando tratamos do indicador relativo à proporção de mestrados, em que todos os docentes o possuem, demonstrando ser um importante pré-requisito para a docência. A principal área de estudo desse nível de formação é a Filosofia e Distúrbios da Comunicação Humana, seguidos da distribuição unitária equânime de Direito, Enfermagem em Saúde Pública, Biologia Celular e Molecular, Ciências Biológicas - Bioquímica Toxicológica, Farmácia, Ciências Odontológicas, Letras e Linguística.

A posse do título de doutor, não atinge a totalidade dos profissionais. Os números mantêm uma constância com os dados demonstrados no nível de mestrado, apresentando formações em Filosofia, acompanhados de Direito, Enfermagem em Saúde Pública, Biologia Celular e Molecular, Ciências Biológicas - Bioquímica Toxicológica, Odontologia Forense e Saúde Coletiva, Educação, Distúrbios da Comunicação Humana - Fonoaudiologia, Letras e Linguística. O pós-doutorado, no que lhe concerne, não faz parte da jornada acadêmica da maioria dos currículos. Os docentes que tiveram a oportunidade desta formação foram distribuídos conforme segue: Enfermagem em Saúde Pública, Ética e Química de Macromoléculas / Especialidade: Proteínas, Desenvolvimento Biotecnológico EnzimologiaProteínas e Políticas Educacionais. 
Foram sistematizados também, dados relacionados às Formações Complementares que possuíam os DeCS "ética" e "bioética" em suas nomenclaturas. Observou-se que a maioria dos docentes não possui formações complementares em ética e bioética. O docente "B" possui destaque enquanto educação permanente na área, no período de 2006 - 2015, com a maior $\mathrm{C} / \mathrm{H}$ destinada a formações. Logo na sequência o docente " $F$ " também possui formações com característica longitudinal, porém com $\mathrm{C} / \mathrm{H}$ menor. Os docentes $\mathrm{A}$ e I possuem apenas uma formação nas áreas estudadas, com destaque para a formação de Yale (realizada também pelo docente B), como sendo um importante programa de verão, promovido pelo Yale Interdisciplinary Center for Bioethics da Yale University.

A análise de similitude das biografias informadas pelos autores (Figura 1) na Plataforma Lattes, transforma em grafo o que o Quadro 1 nos apresenta. Mostra na parte superior esquerda a identificação dos docentes como adjuntos e titulares, que além de ministrar disciplinas, atualmente desenvolvem pesquisas sobre o ensino da filosofia na educação superior.

Figura 1 - Análise de Similitude das Biografias dos Docentes de Ética e Bioética dos cursos de graduação de Fonoaudiologia do RS.



Fonte: Autores (2021). 
O eixo central da imagem estabelece a caracterização pela formação principal dos docentes (Mestrado) e indica também forte ligação com a formação de Doutorado, sugerindo que a realização desse nível foi feita na mesma instituição. As biografias estabelecem também a área de atuação, distribuída em três vertentes: ênfase no ensino da ética; atuação na área da saúde com o tema "proteínas"; epistemologia e filosofia. Ao lado direito da Figura 1, podemos observar o destaque para a atuação como membro de programas de graduação e pós-graduação em Fonoaudiologia.

A produção científica de todos os docentes foi distribuída no Gráfico 1, enquanto a Tabela 1, coloca lado a lado a atuação na área de ética e bioética em detrimento da produção geral enquanto pesquisador, através de indicadores $(n=)$. As categorias selecionadas para a análise, foram: projetos de pesquisa; projetos de extensão; artigos completos publicados em periódicos; livros publicados/organizados ou edições; capítulos de livros publicados.

Gráfico 1 - Comparativo entre atuação em ética, bioética e atuação geral como pesquisador, dos Docentes de ética e bioética dos cursos de graduação de Fonoaudiologia do RS.

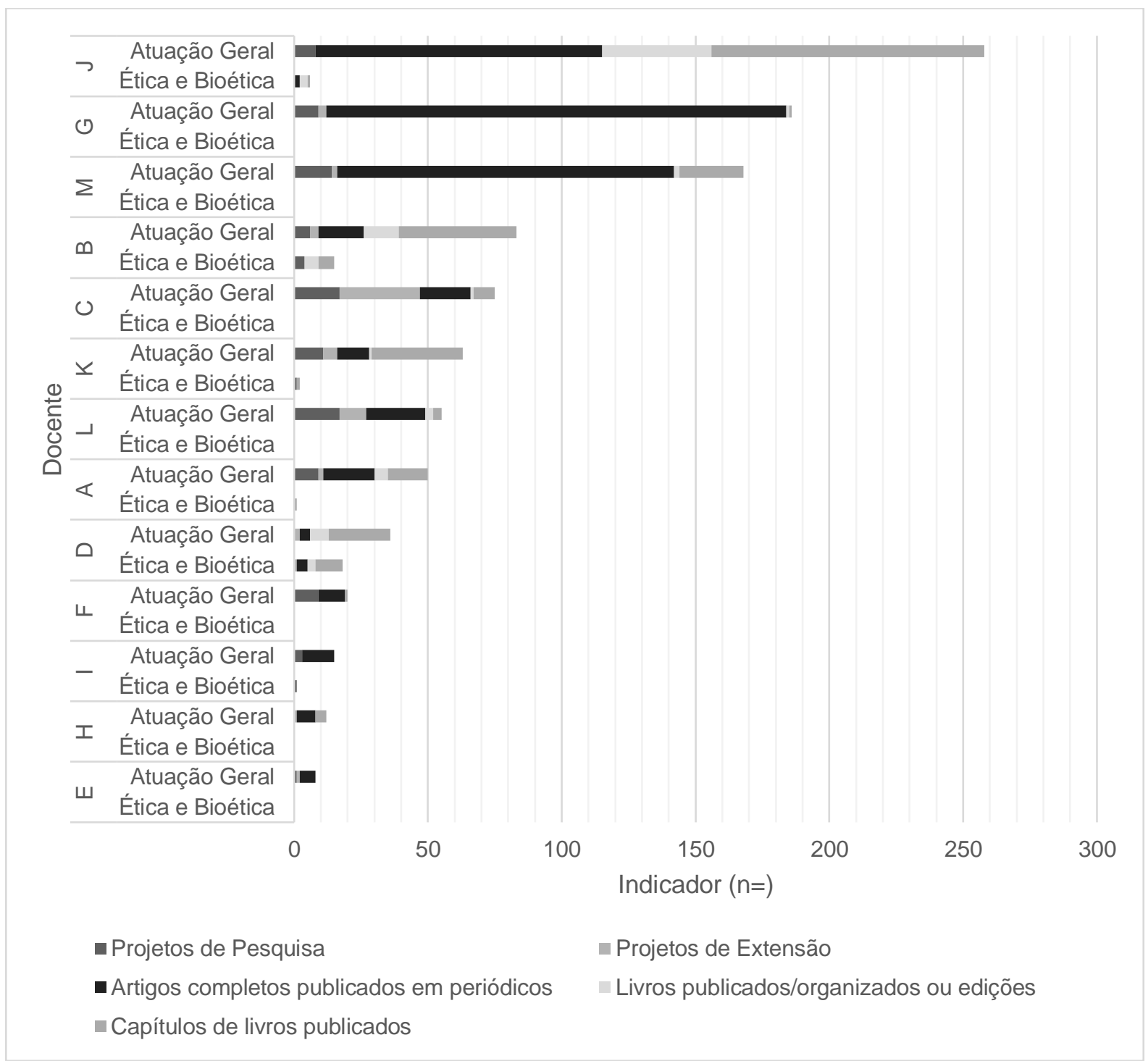

Fonte: Autores (2021). 
Tabela 1 - Distribuição e relação entre produtividade acadêmica total e em ética e bioética dos Docentes dos cursos de graduação de Fonoaudiologia do RS.

\begin{tabular}{|c|c|c|c|c|c|c|c|c|}
\hline $\begin{array}{l}\text { Doc } \\
\text { ent } \\
\text { e }\end{array}$ & & $\begin{array}{l}\text { Proje } \\
\text { tos } \\
\text { de } \\
\text { Pesq } \\
\text { uisa }\end{array}$ & $\begin{array}{l}\text { Proje } \\
\text { tos } \\
\text { de } \\
\text { Exte } \\
\text { nsão }\end{array}$ & $\begin{array}{l}\text { Artigos } \\
\text { completos } \\
\text { publicado } \\
\text { s em } \\
\text { periódicos }\end{array}$ & $\begin{array}{l}\text { Livros } \\
\text { publicados/ } \\
\text { organizados } \\
\text { ou edições }\end{array}$ & $\begin{array}{l}\text { Capít } \\
\text { ulos } \\
\text { de } \\
\text { livros } \\
\text { publi } \\
\text { cados }\end{array}$ & $\begin{array}{l}\text { Indic } \\
\text { ador } \\
\text { es } \\
\text { Totai } \\
\text { s } \\
(n=)\end{array}$ & $\begin{array}{l}\text { Porcentage } \\
\text { m de } \\
\text { produção } \\
\text { em ética e } \\
\text { bioética em } \\
\text { relação à } \\
\text { atuação } \\
\text { geral }(\%)\end{array}$ \\
\hline \multirow[t]{2}{*}{$\overline{\mathbf{A}}$} & Ética e Bioética & $\overline{0}$ & $\overline{0}$ & $\overline{0}$ & $\overline{0}$ & $\overline{1}$ & 8 & \multirow[t]{2}{*}{$16 \%$} \\
\hline & Atuação Geral & 9 & 2 & 19 & 5 & 15 & 50 & \\
\hline \multirow[t]{2}{*}{ B } & Ética e Bioética & 4 & 0 & 0 & 5 & 6 & 15 & \multirow[t]{2}{*}{$18,07 \%$} \\
\hline & Atuação Geral & 6 & 3 & 17 & 13 & 44 & 83 & \\
\hline \multirow[t]{2}{*}{ D } & Ética e Bioética & 0 & 1 & 3 & 3 & 10 & 17 & \multirow[t]{2}{*}{$48,57 \%$} \\
\hline & Atuação Geral & 0 & 2 & 3 & 7 & 23 & 35 & \\
\hline \multirow[t]{2}{*}{$\mathbf{I}$} & Ética e Bioética & 1 & 0 & 0 & 0 & 0 & 1 & \multirow[t]{2}{*}{$6,66 \%$} \\
\hline & Atuação Geral & 3 & 0 & 12 & 0 & 0 & 15 & \\
\hline \multirow[t]{2}{*}{$\mathbf{J}$} & Ética e Bioética & 0 & 0 & 2 & 3 & 1 & 6 & \multirow[t]{2}{*}{$2,32 \%$} \\
\hline & Atuação Geral & 8 & 0 & 107 & 41 & 102 & 258 & \\
\hline \multirow[t]{2}{*}{$\mathbf{K}$} & Ética e Bioética & 1 & 0 & 1 & 0 & 1 & 3 & \multirow[t]{2}{*}{$4,76 \%$} \\
\hline & Atuação Geral & 11 & 5 & 12 & 1 & 34 & 63 & \\
\hline
\end{tabular}

Fonte: Autores (2021).

Quanto ao total das produções indicadas nas áreas de ética e bioética, visualizado na Tabela $1(n=36)$, temos a seguinte distribuição: projetos de pesquisa $(n=6)$; projetos de extensão $(n=1)$; artigos completos publicados em periódicos $(n=4)$; livros publicados/organizados ou edições $(\mathrm{n}=11)$ e capítulos de livros publicados $(\mathrm{n}=15)$.

Os dados mostrados no Gráfico 1 e Tabela 1, apontam disparidades na produção acadêmica dos docentes. Os indicadores gerais do docente $\mathbf{J}(\mathrm{n}=258)$, conforme o Gráfico 1 , possuem uma diferença significativa comparando-os aos docentes que ficam classificados na sequência, em especial na categoria: artigos completos publicados em periódicos. Salienta-se que nesse levantamento foram encontrados seis indicadores de artigos publicados que referiam os DeCS selecionados, sendo que dois desses são de autoria do docente J, embora em consulta nos sites de pesquisa foi constatado que um deles, na verdade, é uma resenha de um livro e o outro não foi encontrado nas bases de dados, publicado como capítulo de livro anos após a sua publicação. Quando comparamos a atuação em ética e bioética com a produção geral, temos uma porcentagem de $2,32 \%$, conforme mostra a Tabela 1 .

Os docentes $\mathrm{G}(\mathrm{n}=186)$ e $\mathrm{M}(\mathrm{n}=168)$, também possuem indicadores distantes dos outros docentes, com ênfase na produção de artigos científicos conforme é possível observar no Gráfico 1. A diferença entre eles está na publicação de capítulos de livros, porém sem relação com os DeCS "ética" e "bioética", bem como nenhum outro indicador relacionado com os descritores estudados nesta pesquisa.

Seguindo a classificação, os docentes B (n=83), C (n=75), K ( $n=63), L(n=55)$ e A $(n=50)$, são semelhantes em número de artigos publicados, conforme visualizamos no Gráfico 1 , mas a atuação se diferencia principalmente na realização de projetos de extensão e capítulos de livros. Além disso, a categoria "projetos de pesquisa" apresenta simultaneamente no currículo dos docentes $\mathrm{C}$ e $\mathrm{L}$ o indicador de $\mathrm{n}=17$ e proximidade nos currículos dos docentes $\mathrm{A}$ $(n=9)$ e $K(n=11)$. 
Merece destaque, ainda na categoria de projetos de pesquisa, o docente $\mathrm{B}$, visto que dos seis projetos apresentados, quatro se referiam aos DeCS ética, dois relacionados ao cinema, ética e saúde, um sobre ética, filosofia e um (já concluído) que tratava do tema bioética e direito. Além de cinco livros e seis capítulos de livros, relacionados aos temas estudados em seus projetos de pesquisa.

O docente $\mathrm{D} \quad(\mathrm{n}=36)$ dedica seu processo de produção de conhecimento, prioritariamente, para a construção de livros e capítulos $(n=30)$, como podemos observar no Gráfico 1 e Tabela 1, embora, cabe destacar que de seus três artigos publicados, todos referem os DeCS "ética" e "bioética" e de seus 26 capítulos de livros publicados, dez deles também indicam os descritores mencionados em seus títulos. Quanto aos artigos publicados por este docente, três deles trouxeram como tema central os DeCS a seguir: Bioética; Oncologia; Saúde; Formação ética; e Ensino de Filosofia. Um quarto artigo, mesmo constando no Lattes como publicado, ainda não havia sido até a data da coleta, porém através da observação do título é possível inferir que se trata de uma análise da concepção bioética sobre aborto, feita por uma personalidade religiosa. Além disso, de 2016 a 2017 participou de um projeto de extensão sobre a constituição ética dos sujeitos, com ações voltadas aos estudantes do ensino médio.

Os docentes $\mathrm{F}(\mathrm{n}=20), \mathrm{I}(\mathrm{n}=15)$ e $\mathrm{H}(\mathrm{n}=12)$, vem dedicando suas atuações em pesquisa, com destaque para o segundo, que possuía até 2016 um projeto de pesquisa que tratava da relação entre Odontologia e Código de Ética. O docente E (n=8), atua em pesquisa, extensão e publica artigos não relacionados aos DeCS pesquisados.

De forma geral, o Gráfico 1 e a Tabela 1 mostram um importante distanciamento entre a atuação dos docentes e suas produções acadêmicas e científicas, quando comparados com os DeCS pesquisados. Além disso, é possível perceber que as maiores atuações apontadas pelos DeCS "ética" e "bioética" são dos docentes D $(n=17)$ e B $(n=15)$ correspondendo a 48,57\% e $31,42 \%$ respectivamente do total de suas produções, conseguindo superar a margem de 10 pontos apontados pelas categorias indicadoras. Seguindo a mesma lógica de demonstrar a porcentagem de produção em ética e bioética, temos o docente $\mathbf{J}$ com seis produções $(2,32 \%)$, seguido do docente K com três $(4,74 \%)$ e dos docentes A $(18 \%)$ e I (6,66\%) com uma produção cada. Outro fato observado, é que mais da metade dos docentes não possuem nenhuma produção relacionada com os DeCS incluídos em seus títulos.

Os artigos completos publicados em periódicos $(n=4)$, tiveram seus resumos e conclusões extraídos e analisados pelo software IRAMUTEQ. O cálculo de frequência de ocorrências gerou o grafo para análise de similitude, conforme mostra a Figura 2. 
Figura 2 - Análise de similitude por frequência de ocorrências dos Resumos e Conclusões, dos artigos publicados pelos Docentes de ética e bioética dos cursos de graduação de Fonoaudiologia do RS, sobre a temática estudada.

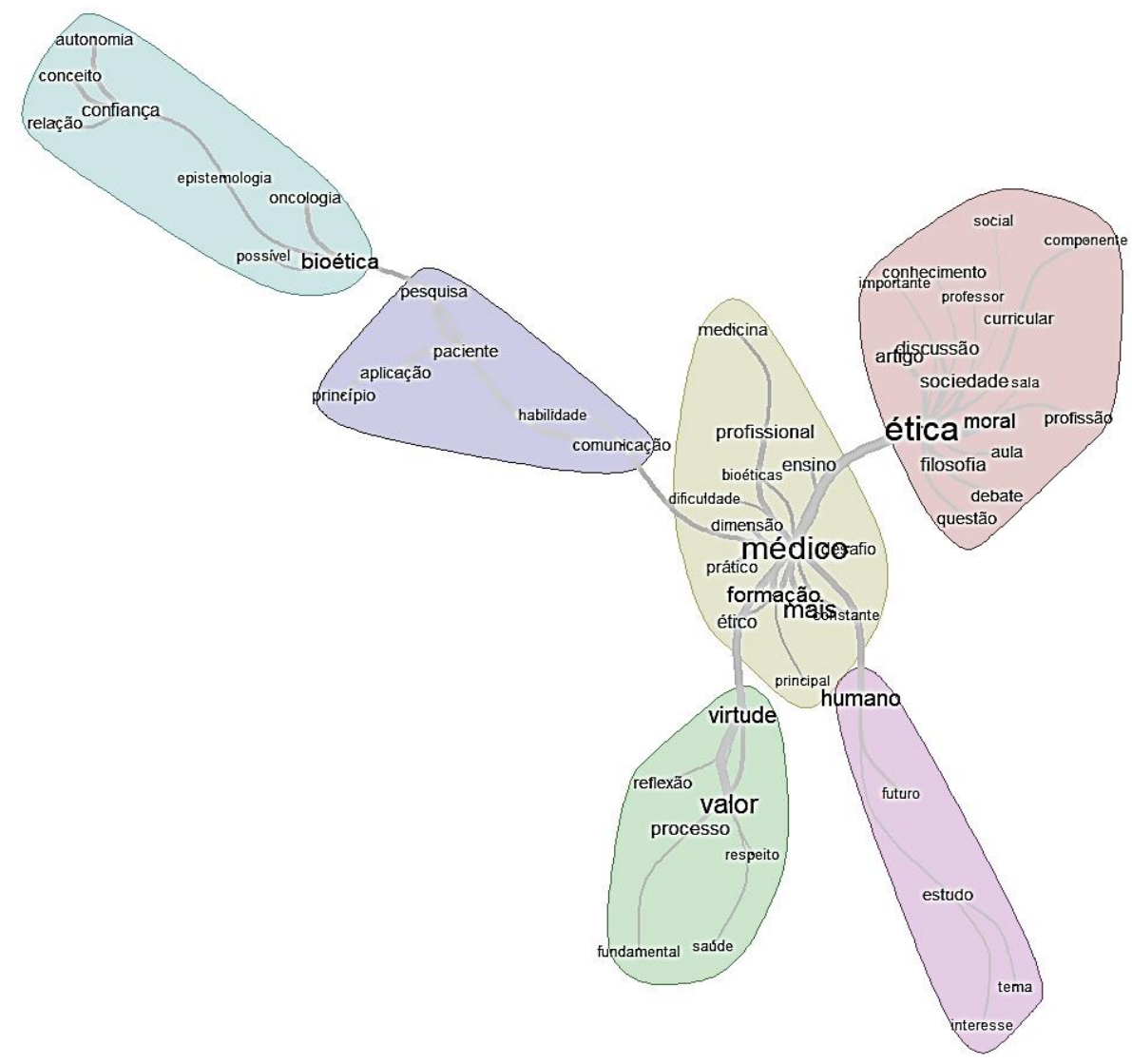

Fonte: Autores (2021).

A análise de frequência e similitude demonstrada pelas conexões e tamanho das palavras, indica que a formação de um médico "mais humano" configura o eixo central e um importante desafio para a dimensão profissional da Medicina. Além disso, é possível perceber que os artigos abordam as questões éticas, destacando tais aspectos como futuro na profissão, fundamentalmente para a prática profissional. Para corroborar com tal análise, na parte inferior da Figura 2 existe forte ligação entre as palavras médico, virtudes e valores conectadas com processo de reflexão e respeito à saúde, como algo fundamental. Destaca-se a presença uniprofissional, representada pela dimensão da formação médica.

A similitude dos artigos também demonstra o interesse na temática de comunicação entre médico e paciente em casos oncológicos, enfatizando essa relação como uma habilidade e colocando a aplicação dos princípios bioéticos como área de interesse para pesquisas e produção de conhecimento. O termo bioética, ainda aparece ligado a epistemologia estabelecendo conceitos e relações entre confiança e autonomia. A formação médica, principalmente relacionada à ética e moral, também é um assunto estudado, conectado às temáticas: currículo, aula, docente, medicina, sociedade, filosofia, habilidades, componente curricular, artigo, discussões e debates sociais.

\section{Discussão}

Essa discussão se inicia a partir da constatação de que uma das IES não possui disciplinas de ética e/ou bioética em sua grade curricular, contrariando inicialmente os dispostos 
das DCN (BRASIL, 2001a) e o Plano Nacional de Educação (BRASIL, 2001b; FINKLER; CAETANO; RAMOS, 2013). Nessa conjuntura, emergem duas hipóteses que podem ser confirmadas ou refutadas por estudos com metodologias específicas para este fim: a primeira se relaciona com a transversalidade na formação, garantindo através de uma sistemática integrada que o conteúdo de ética e bioética perpassa por todas as disciplinas da grade curricular (MOTA; VÉRAS, 2020; SANTOS et al., 2020; WERNECK, 2020). Embora, alguns estudos, já demonstraram resistência dos próprios docentes na implementação desse formato de currículo (FORMIGLI et al., 2010; MOTA; VÉRAS, 2020). A segunda alternativa, é a presença do currículo oculto que conta com a postura ética e moral de todos os docentes do curso, servindo como modelo para a formação dos discentes, em detrimento de comportamentos não éticos expostos pelos próprios docentes, marcando o processo de ensino-aprendizagem dos alunos, dado que, comportamento é consequência da internalização de princípios e valores (ABRAHÃO, 2018; BURGATTI; BRACIALLI; OLIVEIRA, 2013; FERREIRA; MOURÃO; ALMEIDA, 2016). Desse modo, destaca-se a importância de espaços formais de reflexões críticas sobre comportamento, na prática profissional (FINKLER; CAETANO; RAMOS, 2013).

Outra análise apontada pelo estudo pode ser feita pelo expressivo número de mulheres, haja vista, a conquista da paridade em 2010, quanto ao gênero dos registrados no CNPq, quando os 128,6 mil pesquisadores relacionados na base de dados, estavam divididos igualmente entre homens e mulheres. Também naquele ano, o número de mulheres (52\%) ultrapassou o de homens (48\%), como líderes dos grupos de pesquisa registrados no CNPq (LAZZARINI et al., 2018). Os dados são crescentes como mostra uma pesquisa que identificou no período analisado (1996 - 2010), a proporção de 60\% para homens e 40\% para mulheres (BOLZANI, 2017), porém a conquista de igualdade ainda é uma luta de todos, como mostra o número total de bolsas outorgadas pelo $\mathrm{CNPq}$ no Brasil (em todos os níveis acadêmicos), através do qual encontramos as maiores desigualdades de gênero em Ciências Exatas e da Terra $(34,2 \%$ mulheres), em Engenharia e Computação (36,5\% mulheres) e Ciências da Saúde (68\% mulheres) (LAZZARINI et al., 2018).

A formação acadêmica dos docentes também pode se transformar em objeto de análise, já que, dos 13 currículos analisados apenas quatro são bacharéis em Fonoaudiologia. O que se deve considerar neste sentido são as diversas pesquisas que indicam a casuística como o método mais adequado para o ensino da ética e da bioética (COELHO; PARTELLI, 2019; JUNGES, 2005; LEITE et al., 2017), estariam docentes, que não são da área da Fonoaudiologia suficientemente preparados para lidar como estudos de casos práticos? Por outro lado, Fonoaudiólogos, teriam imersão teórica suficiente para lecionar tais disciplinas, se não possuem indicadores em nenhuma categoria apontada por este estudo, com a presença de DeCS ética e bioética?

Estes questionamentos podem ser respondidos, se entendermos que a formação profissional é composta por três aspectos: teoria, prática e reflexão (COSME; VALENTE, 2020). Sendo assim, o discente de Fonoaudiologia mantém essa preocupação com a relação entre a teoria e a prática, muitas vezes em seus estágios clínicos, vivendo problemas éticos concomitantes com suas responsabilidades e preocupações inerentes à vida acadêmica, cabendo ao docente a escuta qualificada e a expressão dos pilares constitutivos da formação do alunoFonoaudiólogo: a articulação da teoria e prática, o autoconhecimento e a interação com os docentes (MISRAHL, 2001)

A transmissão de conhecimento não pode ser vista como um aglutinado de conteúdo, mas sim, um programa sistemático que inclui a percepção de mundo, de modo que, os docentes para além de reproduzir informações, formam cidadãos, com técnicas contextualizadas à 
realidade, percebendo os indivíduos com ética e singularidade (CARDOSO et al., 2017; FREIRE, 1997). De modo geral, as profissões da área da saúde possuem formações mais tecnicistas, com contato limitado com a didática e planejamento, por isso a importância da educação permanente (ARANTES et al., 2017), também para os docentes de nível superior, que se demonstrou discreta apenas em quatro currículos com formações complementares.

A biografia dos docentes, demonstrada pelo grafo para análise de similitudes (Figura 1), corroborou com os dados relativos à formação dos mesmos, com destaque para a presença de $100 \%$ de docentes Mestres e grande maioria de Doutores, característica já esperada, visto que, a legislação (BRASIL; BRASIL, 1996) exige que um terço do corpo docente das instituições universitárias, tenha titulação acadêmica de mestrado ou doutorado. Cabe destacar, no entanto, que a presença dos DeCS ética e bioética teve uma frequência de quatro (A, B, I e J) e dois (A e D), respectivamente, demonstrando que somente cinco docentes informaram em sua biografia que possuem alguma identificação com as áreas estudadas. Além disso, somente o docente D possui em seu processo de formação acadêmica (pós-doutorado) o DeCS ética.

Percebe-se aqui, a necessidade dos docentes se aproximarem da ética em suas diferentes formas de concepção, e não apenas limitada à pesquisa com seres humanos ou a ética profissional (deontologia), por exemplo (ANDRADE; GIVIGI; ABRAHÃO, 2017; FINKLER; CAETANO; RAMOS, 2013; FOUCAULT; MOTTA, 2008; NÓBREGA et al., 2015). Quando os docentes reconhecerem o seu papel no desenvolvimento moral dos estudantes, atuando como bons modelos profissionais e contribuindo para transformar o ensino por práticas humanizadas e humanizadoras, espera-se que todas as biografias tragam os DeCS buscados nesta pesquisa (FINKLER; CAETANO; RAMOS, 2013; FREIRE, 1997; WERNECK, 2020).

Os resultados também demonstram grande disparidade entre a atuação geral dos docentes e a atuação específica em ética e bioética. Algumas inferências podem ser feitas a partir desse achado quando consideramos outros aspectos apontados pelo estudo: formação do docente em área do conhecimento diversa; não identificação com as temáticas (FERREIRA; MOURÃO; ALMEIDA, 2016); variação de tempo entre a atuação dos pesquisadores (LEITE et al., 2017); produtivismo acadêmico ao qual os docentes são submetidos (TEIXEIRA; MARQUEZE; MORENO, 2020; VOSGERAU et al., 2017; YAMAMOTO et al., 2012); distribuição de sua carga horária ministrando outras disciplinas, orientações, atividades de gerenciamento e projetos (TEIXEIRA; MARQUEZE; MORENO, 2020).

Os artigos publicados pelos docentes com os DeCS ética ou bioética nos títulos, tiveram como tema central a formação em Medicina, a preocupação com a desumanização dos egressos e o processo de degradação da empatia. Tais aspectos segundo estudos, são proporcionados pela própria evolução do curso, em detrimento à pressão e ao estresse quando estão sobrecarregados com atividades e responsabilidades, podendo contribuir para perda da qualidade de vida e ocasionar o esgotamento emocional ou Burnout (AMORE FILHO et al., 2018; BATLEY et al., 2016; PARO et al., 2014). Foi possível perceber também, que a construção de valores e virtudes, durante o processo de formação é fundamental para a prática profissional (AMORIM; ARAÚJO, 2013; GIUBILINI; MILNES; SAVULESCU, 2016; MOTA; VÉRAS, 2020).

No que tange a ética no ensino da Medicina, reafirma-se a presença enquanto componente curricular, por ser um importante conhecimento a ser debatido em sala de aula, reforçando a necessidade da ampliação do conceito de saúde e sociedade. Além disso, os modelos pedagógicos também devem estar contextualizados às novas dinâmicas da estrutura social (DANIEL; PESSALACIA; ANDRADE, 2016; FERREIRA; MOURÃO; ALMEIDA, 2016; FREIRE, 1997; WERNECK, 2020), existam currículos com a introdução de disciplinas 
que permitam a abordagem da temática da humanização, a retomada da relação com as artes, para favorecer a reflexão e aplicação de cenários favoráveis à sensibilização dos profissionais, e a ênfase na relação médico-paciente de maneira mais harmoniosa (AMORE FILHO et al., 2018; HARBELL et al., 2020). Embora as temáticas abordadas pelos artigos voltados à área médica sejam, em sua maioria, multiprofissionais, há de se destacar a necessidade de reflexões produzidas através de estudos específicos da área da Fonoaudiologia, visando uma construção identitária profissional, assim como a aproximação de saberes não dissociados da prática, ensino, pesquisa e extensão (YAMAMOTO et al., 2012).

A comunicação entre médico e paciente também surge como uma temática dos estudos e necessária abordagem na formação, funcionando como ferramenta para o estabelecimento e fortalecimento do cuidado (GONZALEZ; BRANCO, 2012; SILVA; SOUSA; RIBEIRO, 2018; SUCUPIRA, 2007). Além disso, a temática reafirma a preocupação com a necessidade de consonância entre a formação médica, o processo de humanização da assistência à saúde e os fatores psicossociais que envolvem o tema da morte (BONAMIGO; DESTEFANI, 2010; FREIBERGER; CARVALHO; BONAMIGO, 2019; SANTOS; LINS; MENEZES, 2018; ZANATTA et al., 2020). A limitação humana de lidar com a dor e com o sofrimento, condições comuns no cotidiano médico, pode motivar como autoproteção o afastamento entre o profissional e os pacientes (AMORE FILHO et al., 2018; GONZÁLEZ BLASCO, 2010). Assim, como já mencionado, a abordagem uniprofissional da produção acadêmica dos docentes impossibilita reflexões específicas da Fonoaudiologia enquanto profissão, a exemplo da contradição ocasionada por essencialmente ser uma profissão que trata dos distúrbios da comunicação humana, mas que não possui total dimensão desse conceito de "comunicação" em sua formação, podendo impactar na qualidade do atendimento integral e humanizado dos sujeitos (AVENDANO et al., 2021).

Por fim, a confiança e a autonomia tiveram seus conceitos relacionados à epistemologia do testemunho e à Bioética. Essa interseção, destaca que em determinados momentos, quando se observa o testemunho de uma pessoa, alguém acredita no conteúdo proposto, e essa "transição" do testemunho para a verdade, pode ser inconsciente em dados momentos. Por outro lado, temos situações verdadeiras, que necessitam de fontes confiáveis para atestá-las (PLASTINO, 2017). No caso da Bioética e nas relações médico-paciente, a medicina contemporânea e o avanço das tecnologias contribuíram para a quebra da confiança, devido à relação assimétrica de conhecimento e poder, havendo uma valorização da anuência como sinônimo de autonomia expressa na escolha de tratar-se ou não, porém autonomia implica reconhecimento recíproco em relações de respeito, cuidado e estima (FREIRE, 1997; MINAHIM, 2020; RANGEL, 2009).

\section{Considerações finais}

Os achados desta pesquisa não possuem a prerrogativa de apontar fraquezas ou expor deficitariedades na formação ética e bioética do Fonoaudiólogo no RS. São disparadores de uma discussão que precisa urgentemente ser retomada para garantir o futuro da profissão. A carência de espaços de debate sobre estas temáticas, como fóruns, congressos e seminários, por exemplo, desmobiliza a articulação de saberes e participação ativa e coletiva de toda a classe Fonoaudiológica, na construção do embasamento legal da atuação.

De certo modo, ao que se percebe, a ética em Fonoaudiologia, perde espaço na grade curricular chegando a ser extinta ou ministrada por docentes que não possuem no seu perfil acadêmico e produção científica imersão nas temáticas, como mostrado aqui. Além disso, a perspectiva de docentes que não possuem a formação básica em Fonoaudiologia, reforça a 
necessidade de fortalecer o debate sobre a formação e novas pesquisas sobre ementas de conteúdos abordados, para sabermos efetivamente, quem ensina e o que se ensina aos graduandos de Fonoaudiologia.

Outrossim, a pesquisa em ética e bioética apontada por esse estudo, enfatiza a formação médica, que em suas especificidades, não representa a formação em saúde globalmente e muito menos em Fonoaudiologia. Talvez o déficit de pesquisas específicas sobre a formação de Fonoaudiólogos e não a tomada de pesquisas de outras áreas como sínteses do ensino da Fonoaudiologia, seja justamente um dos motivos pelo qual as DCN em Fonoaudiologia foram revistas e, em breve, serão republicadas.

Espera-se que esses apontamentos possam fomentar discussões quanto ao perfil docente das disciplinas de ética e bioética na formação dos Fonoaudiólogos do Rio Grande do Sul. Outros estudos devem ser elaborados no intuito de qualificar essa análise, possibilitando também a escuta dos docentes das temáticas, de modo a produzir uma construção avaliativa coletiva do ensino, propondo as transformações necessárias para a ressignificação e ampliação de espaços acolhedores de um olhar crítico e reflexivo na formação.

\section{Referências}

ABRAHÃO, G. S. O ensino da bioética para a formação acadêmica dos profissionais de saúde. Jornal de Ciências Biomédicas E Saúde, v. 3, n. 2, p. 107, 2018.

ALCÂNTARA, F. A. Dilemas éticos em cuidados paliativos: revisão de literatura. Revista Bioética, v. 28, n. 4, p. 704-709, dez. 2020.

AMORE FILHO, E. D. et al. Ações para a Retomada do Ensino da Humanização nas Escolas de Medicina. Revista Brasileira de Educação Médica, v. 42, n. 4, p. 14-28, dez. 2018.

AMORIM, K. P. C.; ARAÚJO, E. M. DE. Formação ética e humana no curso de medicina da UFRN: uma análise crítica. Revista Brasileira de Educação Médica, v. 37, n. 1, p. 138-148, 2013.

ANDRADE, E. O. DE; GIVIGI, L. R. P.; ABRAHÃO, A. L. A ética do cuidado de si como criação de possíveis no trabalho em Saúde. Interface: Comunicação, Saúde, Educação, 19 out. 2017.

ARANTES, B. et al. As ações do Núcleo Docente Estruturante no processo de educação permanente dos professores em um curso de graduação em Odontologia. Scientific Investigation in Dentistry, v. 22, p. 19, 30 nov. 2017.

AVENDANO, C. G. et al. Conceito da Comunicação na formação dos fonoaudiólogos no ensino público do Rio Grande do Sul. Revista Sustinere, v. 9, n. 1, p. 354-371, 2021.

BATLEY, N. J. et al. Cynicism and other attitudes towards patients in an emergency department in a middle eastern tertiary care center. BMC medical education, v. 16, p. 36, 29 jan. 2016.

BOLZANI, V. DA S. Mulheres na ciência: por que ainda somos tão poucas? Ciência e Cultura, v. 69, n. 4, p. 56-59, out. 2017. 
BONAMIGO, E. L.; DESTEFANI, A. DOS S. A dramatização como estratégia de ensino da comunicação de más notícias ao paciente durante a graduação médica. Rev. bioét. (Impr.), v. 18, n. 3, dez. 2010.

BRASIL. Parecer CNE/CES n. 1.210 de 07 de dezembro de 2001. Estabelece as Diretrizes Curriculares Nacionais dos Cursos de Graduação em Fisioterapia, Fonoaudiologia e Terapia Ocupacional. Conselho Nacional de Educação. Diário Oficial da União, 2001a.

BRASIL, C.; BRASIL. Lei n ${ }^{\circ}$ 9.394, de 20 de dezembro de 1996. Estabelece as diretrizes e bases da educação nacional. Diário Oficial da União, v. 134, n. 248, 1996.

BRASIL, C. DE. Lei n ${ }^{0} 10.172$, de 9 de janeiro de 2001. Aprova o Plano Nacional de Educação e dá outras providências. Diário Oficial da União, 2001 b.

BURGATTI, J. C.; BRACIALLI, L. A. D.; OLIVEIRA, M. A. DE C. Problemas éticos vivenciados no estágio curricular supervisionado em Enfermagem de um currículo integrado. Rev. Esc. Enferm. USP, v. 47, n. 4, p. 937-942, ago. 2013.

CAMARGO, B. V.; JUSTO, A. M. IRAMUTEQ: um software gratuito para análise de dados textuais. Temas em Psicologia, v. 21, n. 2, p. 513-518, dez. 2013.

CARDOSO, M. L. DE M. et al. A Política Nacional de Educação Permanente em Saúde nas Escolas de Saúde Pública: reflexões a partir da prática. Ciência \& Saúde Coletiva, v. 22, p. 1489-1500, maio 2017.

CARRAPATO, P.; CORREIA, P.; GARCIA, B. Determinante da saúde no Brasil: a procura da equidade na saúde. Saúde e Sociedade, v. 26, p. 676-689, set. 2017.

CASSETTARI, R.-R.-B. et al. Comparação da Lei de Zipf em conteúdos textuais e discursos orais. Profesional de la Información, v. 24, n. 2, p. 157-167, 11 mar. 2015.

COELHO, M. P.; PARTELLI, A. N. M. Júri simulado no ensino da ética/bioética para a enfermagem. Rev. enferm. UFPE on line, v. 13, n. 2, p. 499-510, fev. 2019.

COSME, F. S. M. N.; VALENTE, G. S. C. Educação permanente na práxis de preceptoria em Atenção Básica de Saúde. Research, Society and Development, v. 9, n. 8, p. e653984490e653984490, 24 jul. 2020.

COSTA, D. A. S. et al. Diretrizes curriculares nacionais das profissões da Saúde 2001-2004: análise à luz das teorias de desenvolvimento curricular. Interface - Comunicação, Saúde, Educação, 6 ago. 2018.

DANIEL, J. C.; PESSALACIA, J. D. R.; ANDRADE, A. Debate interdisciplinar no processo ensino aprendizagem em bioética: experiências de acadêmicos da área da saúde. Invest educ enferm [internet], v. 34, n. 2, p. 288-296, 2016.

DAVYT, A.; VELHO, L. A avaliação da ciência e a revisão por pares: passado e presente. Como será o futuro? História, Ciências, Saúde-Manguinhos, v. 7, n. 1, p. 93-116, 2000.

FERREIRA, L. C.; MOURÃO, R. A.; ALMEIDA, R. J. DE. Perspectivas de docentes de medicina a respeito da ética médica. Rev. bioét. (Impr.), v. 24, n. 1, p. 118-127, abr. 2016. 
FINKLER, M.; CAETANO, J. C.; RAMOS, F. R. S. Ética e valores na formação profissional em saúde: um estudo de caso. Ciênc. saúde coletiva, v. 18, n. 10, p. 3033-3042, out. 2013.

FORMIGLI, V. L. et al. PROJETO POLÍTICO-PEDAGÓGICO DO CURSO DE GRADUAÇÃO EM MEDICINA DA FMB/UFBA. Gazeta Médica da Bahia, v. 0, n. 1, 19 out. 2010.

FOUCAULT, M.; MOTTA, M. B. DA. Arqueologia das ciências e história dos sistemas de pensamento. Arqueologia das ciências e história dos sistemas de pensamento, p. lii,376lii,376, 2008.

FREIBERGER, M. H.; CARVALHO, D. DE; BONAMIGO, E. L. Comunicação de más notícias a pacientes na perspectiva de estudantes de medicina. Revista Bioética, v. 27, n. 2, p. 318-325, 1 jul. 2019.

FREIRE, P. Pedagogía de la autonomía: saberes necesarios para la práctica educativa. [s.l.] siglo XXI, 1997.

GIUBILINI, A.; MILNES, S.; SAVULESCU, J. The Medical Ethics Curriculum in Medical Schools: Present and Future. The Journal of Clinical Ethics, v. 27, n. 2, p. 129-145, 2016.

GONZÁLEZ BLASCO, P. É possível humanizar a Medicina? Reflexões a propósito do uso do Cinema na Educação Médica. Mundo saúde (1995), p. 357-367, 2010.

GONZALEZ, R. F.; BRANCO, R. Reflexões sobre o processo ensino-aprendizagem da relação médico-paciente. Rev. bioét. (Impr.), v. 20, n. 2, ago. 2012.

HARBELL, M. W. et al. Teaching Systems Improvement to Early Medical Students:

Strategies and Lessons Learned. Acad Med, v. 95, n. 1, p. 136-144, 2020.

JUNGES, J. R. Bioética como casuística e como hermenêutica. Rev Bras Bioética, v. 1, n. 1, p. 41, 2005.

LAZZARINI, A. B. et al. Mulheres na Ciência: papel da educação sem desigualdade de gênero. Revista Ciência em Extensão, v. 14, n. 2, p. 188-194, 30 jun. 2018.

LEITE, A. F. et al. Fatores condicionantes de saúde relacionados ao trabalho de professores universitários da área da saúde: uma revisão integrativa. Revista Brasileira de Saúde Ocupacional, v. 42, 2017a.

LEITE, D. A. A. et al. Uso da casuística no processo ensino-aprendizagem de bioética em saúde. Revista Bioética, v. 25, n. 1, p. 82-88, abr. 2017 b.

MARCHAND, Pascal; RATINAUD, Pierre. L'analyse de similitude appliquée aux corpus textuels: les primaires socialistes pour l'élection présidentielle française (septembre-octobre 2011). Actes des 11eme Journées internationales d'Analyse statistique des Données Textuelles. JADT, v. 2012, p. 687-699, 2012.

MINAHIM, M. A. A autonomia na relação médico-paciente: breves considerações. Cadernos Ibero-Americanos de Direito Sanitário, v. 9, n. 1, p. 85-95, 2020. 
MISRAHL, D. D. Transformação e formação: o aluno-fonoaudiólogo. A clínica fonoaudiológica em questão, p. 105, 2001.

MOTA, J. C.; VÉRAS, R. M. Eixo ético-humanístico da Faculdade de Medicina da Bahia: percepção dos estudantes. Revista Bioética, v. 28, n. 2, p. 319-331, 26 jun. 2020.

NÓBREGA, L. M. DA et al. A experiência de estudantes de Odontologia com dilemas éticos. Revista da ABENO, v. 15, n. 4, p. 10-18, 2015.

PARO, H. B. M. S. et al. Empathy among medical students: is there a relation with quality of life and burnout? PloS One, v. 9, n. 4, p. e94133, 2014.

PINHO, M. J. DE. Ciência e ensino: contribuições da iniciação científica na educação superior. Avaliação: Revista da Avaliação da Educação Superior (Campinas), v. 22, p. 658-675, 2017.

PIROLA, S. B. DE F. B. et al. A IMPORTÂNCIA DA INICIAÇÃO CIENTÍFICA NA GRADUAÇÃO DE MEDICINA. Revista Corpus Hippocraticum, v. 1, n. 1, 1 abr. 2020.

PLASTINO, C. E. O conhecimento com base no testemunho. Discurso, v. 47, n. 2, p. 9-24, 2017.

RANGEL, V. M. A crise dos vínculos de confiança nas interações da prática médica: uma nova configuração no contexto histórico contemporâneo. Physis: Revista de Saúde Coletiva, v. 19, p. 239-242, 2009.

SANTOS, A. F. N. et al. A bioética como tema transversal na formação do enfermeiro em um currículo integrado: análise documental/ Bioethics as a cross-theme in nursery training in an integrated curriculum: documental analysis. Brazilian Journal of Development, v. 6, n. 1, p. 2463-2477, 16 jan. 2020.

SANTOS, M. R. C.; LINS, L.; MENEZES, M. S. "As intermitências da morte" no ensino da ética e bioética. Revista Bioética, v. 26, n. 1, 20 mar. 2018.

SILVA, A. E.; SOUSA, P. A.; RIBEIRO, R. F. Comunicação de notícias difíceis: percepção de médicos que atuam em oncologia. Rev. enferm. Cent.-Oeste Min, v. 8, p. [1-8], mar. 2018.

SOUZA, T. P. DE et al. Tipos de Pesquisa Quanto Aos Procedimentos ou Escolha do Objeto de Estudo. In: Fundamentos Teóricos e Metodológicos da Pesquisa em Educação em Ciências. 1. ed. Curitiba PR: Bagai, 2021. v. 1p. 158.

SUCUPIRA, A. C. A importância do ensino da relação médico-paciente e das habilidades de comunicação na formação do profissional de saúde. Interface: Comunicação, Saúde, Educação, v. 11, p. 624-627, dez. 2007.

TEIXEIRA, T. DA S. C.; MARQUEZE, E. C.; MORENO, C. R. DE C. Produtivismo acadêmico: quando a demanda supera o tempo de trabalho. Revista de Saúde Pública, v. 54, p. 117, 2020. 
VOSGERAU, D. S. R. et al. Produtivismo Acadêmico e Suas Repercussões no Desenvolvimento Profissional de Professores Universitários. Educação \& amp; Sociedade, v. 38, n. 138, p. 231-247, jan. 2017.

WERNECK, R. R. A dimensão ética na formação em Odontologia no Brasil: panorama e vertentes. Revista Sítio Novo, v. 4, n. 4, p. 112-123, 1 out. 2020.

YAMAMOTO, O. H. et al. Produção científica e "produtivismo": há alguma luz no final do túnel? Revista Brasileira de Pós-Graduação, v. 9, n. 18, 31 dez. 2012.

ZANATTA, F. N. et al. Morte digna: percepção de médicos de hospital de ensino. Revista Bioética, v. 28, n. 1, p. 119-127, 30 mar. 2020.

Recebido em abril de 2021.

Aprovado em outubro de 2021. 